\title{
An Empirical Study on Flipped Classroom in College English Teaching Based on the Application of SPOC and Mobile Internet Technology
}

\author{
Xiaodan Xi and Maochun Chen
}

\author{
Xiaodan Xi: Foreign Language Department , East University of Heilongjiang , Harbin, Heilongjiang \\ Province, China , 150066 ; \\ Maochun Chen : The School of Western Studies, Heilongjiang University, Harbin, Heilongjiang \\ Province, China, 150080 \\ 38392785@qq.com,
}

Key words: SPOC; Mobile Internet; Flipped Classroom; Empirical Study

\begin{abstract}
With the rapid development of mobile Internet technology in this Big Data era, the rising and integrating of 5 products or services based on IP technologylay solid foundation for its rapid development. Meanwhile, the emergence of e-learning, distance education, mobile terminal, online learning and e-educationmakes learners change their learning style-from static learning to dynamic learning, which promotes the Flipped Classroom in the teaching reform. In this paper, an innovative teaching mode is discussed-Flipped Classroom in College English Teaching based on the application of SPOC and mobile Internet technology, which represents a new teaching mode that features personalized learning. Through analysis of advantages and disadvantages, feasibility and directional research are expected to contribute to rationalization of future teaching.
\end{abstract}

\section{Study on the Status Quo of Flipped Classroom Development Led by Mobile Internet Technology in China}

10-Year Development Plan for Education Informationization(2011-2020)put forward thatto advance the development of education sector with the education modernization through education informationization, we should give full play to the strength of information technology and attach great importance to the deep and comprehensive integration of IT and education, improving teaching mode and pushing ahead withthe education reform.TheDepartment of Higher Education(2007.1) pointed out that foreign language education should be aimed at developing students' practical capability to use foreign language. College English, a compulsory foundation course, is aimed at developing and improving students' comprehensive language ability and cultural accomplishment, which makes it possible that English teaching and learning could not be limited by time and place and which makes English teaching and learning personalized and independent. Flipped Classroom or Inverted Class studies just started in recent years. These studies mainly focus on three aspects, such as the basic teaching philosophy, the application of FC integrated with IT and some specific ways and methods of its application. Zhang Jinlei integrate FC with games, thus creating a game-based teaching mode, which proved to be effective byempirical studies. Zhong Xiaoliu from Tsinghua University integrated FC with Tai Chi philosophy, and a circular teaching mode was created then. Prof. Ma Xiulin from Beijing Normal University conducted a research on Flipped Classroom Mode (FCM) and then he tried to apply it to the college IT teaching. Finally, through examining the differencesof experimental group and control group, analysis and discussion on the way, the range and limitation of FCM application were conducted. Prof. Song Zhaoxia applied FCM to her program teaching, which makes it possible to acquire knowledge through the 
Internet and which could help students recombine and allocate the time knowledge internalization needs.

\section{The Empirical Researches of SPOC Teaching Model Building on English Teaching}

\subsection{The Definition of SPOC}

SPOC (Small Private Online Course) is a small-scale personalized online course by setting parameters and access criterion which is made up of micro video, just-in-time learning, interactive discussion and study quiz etc. ${ }^{[4]}$ SPOC has overcome some drawbacks of MOOC, such as the setting of course objectives, the choice of teaching objects, degree of difficulty and prior knowledge students have accumulated, therefore localizing the digital information of learning terminals. Kang Yeqin and Professor Robert.Lu of Harvard University think that teaching videos and traditional method of duplicating class teaching can be set apart through such a way of learning, which will make leaners exposed to livelier teaching experience, study in a more effective way and get their learning results enhanced. ${ }^{[5]}$

2.2 The Building of SPOC-based English Flipped Classroom

The building of flipped classroom based on SPOC is shown in figure-1. It is divided into online and offline learning systems by leveraging campus resources to establish learning platform and software system. Before the class, teachers set teaching goals, provide teaching resources, design teaching scenes and record teaching videos (well-targeted ones), while students understand projects and their evaluation, watch teaching videos and finish quiz in sub-projects and give feedback of difficult points in projects; during the class, teachers keep track of the development of teaching, take part in seminars with the task force involved in projects, offer inspiration to help solve difficult problems in projects and finish evaluation and assessment. Meanwhile, students grasp knowledge about projects, solve problems through brainstorming, finish tasks and evaluate each other's achievements. After the class, teachers summarize students' feedback so as to enrich project resources and students review knowledge about projects to improve English skills. 


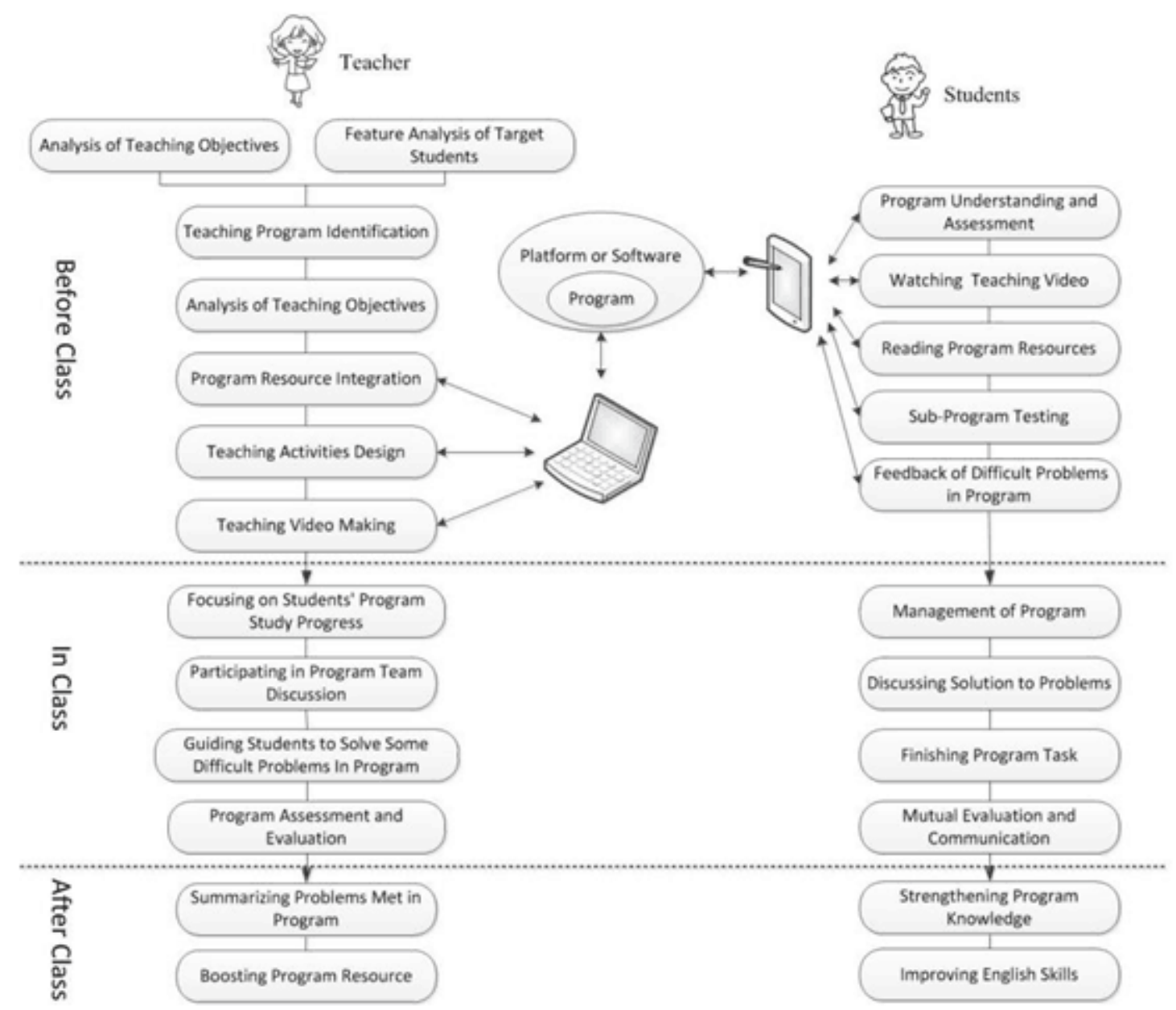

Figure 1 The Construction of SPOC-based Flipped Classroom

\subsection{The Analysis of Content}

The researches on innovative model of college English based on SPOC have a clear teaching goal: by harnessing the diversified learning mode of flipped classroom, it makes learners independent thinkers and feel untrammeled in acquiring knowledge by themselves, which demonstrates the heuristic mode of teaching and enable students to study in a more self-regulated way. Teaching contents are divided into two dimensions: online and offline learning and three parts: before, during and after the class. By capitalizing on online platform and learning resources, students look through projects, finish the quiz and give feedback on difficult points before class; they solve specific problem through discussing, finish project task and master relevant knowledge during class; and they review and reinforce the knowledge in view of improving their comprehensive ability to use English. Such a three-in-one teaching mode not only realizes personalized learning process but also combines practicality, instructiveness and entertainment. In terms of teaching organizing, SPOC teaching mode overcomes the shortcoming of MOOC, enabling harmonious interactions between teachers and students. When class period is reduced, a seamless connection is formed to help students give feedback and solve problems timely, thus giving students a sense of belonging and purpose in English learning under SPOC. In terms of teaching evaluation, breakdown practices including listening, speaking, reading, writing, translating are finished through platform, Internet system and online and offline classes. Diversified learning dimension avoids the disadvantages of traditional teaching mode in that it helps teachers to design courses, achieve teacher assessment, self-assessment and peer-assessment and solve students' problems in a well-targeted manner. Synchronizing comments and feedbacks and solving "thorny problems" in a 
visualized way greatly boost students' confidence and learning ability, which help improve teaching and course design in turn.

\section{The Analysis on The Teaching Effects of SPOC-based Mobile Internet Flipped Classroom}

\subsection{Questionnaire Survey}

To further validate the teaching effects of SPOC-based Internet flipped classroom, we take the course Virtual Operation of Internet platform-based Global Commerce as an example. 150 students in class of 2013 and 2014 in business English major are taken as the subject, which is composed of 18 boys and 132 girls. The content of this survey is comment on the teaching effects of SPOC-based flipped classroom, which includes: whether SPOC-based flipped classroom can enhance study results, improve efficiency and stimulate learning interest. As is shown in table-1:

Figure1 The Learning results of SPOC-based Flipped Classroom

\begin{tabular}{cccc}
\hline & Agree & Disagree & No Difference \\
\hline Enhancing Result & $81 \%$ & $10 \%$ & $9 \%$ \\
Improving & $76 \%$ & $4 \%$ & $20 \%$ \\
Efficiency & & & \\
Stimulating Interest & $60 \%$ & $15 \%$ & $25 \%$ \\
\hline
\end{tabular}

As is shown in the above table, students that think learning results are enhanced account for $81 \%$ while $10 \%$ think the opposite and another $9 \%$ take it lightly; the proportion for the segment of improving efficiency is $76 \%, 4 \%$ and $20 \%$ respectively; the proportion for the segment of stimulating interest is $60 \%, 15 \%$ and $25 \%$ respectively. From the above figures we can see that SPOC-based flipped classroom satisfy students' diversified learning needs in the era of Internet to a large extent. Merged with the methods of MOOC and avoiding its disadvantages, it takes the teaching effects to a higher level to some extent.

3.2 Analysis and Discussion on Test Results through SPSS

After a year of test, we contrast the test result of experimental and control groups and the results obtained through SPSS data analysis are shown is table-2:

Figure 2 The test result of experimental and control groups

\begin{tabular}{|c|c|c|c|c|}
\hline & Group & Average Score & $\mathrm{t}$ & $\mathrm{p}$ \\
\hline \multirow[t]{2}{*}{ Pretest } & $\begin{array}{l}\text { Experimental } \\
\text { Group } \\
(\mathrm{N}=150)\end{array}$ & 77.31 & 0.17 & 0.74 \\
\hline & $\begin{array}{l}\text { Control Group } \\
(\mathrm{N}=150)\end{array}$ & 77.12 & & \\
\hline \multirow[t]{2}{*}{ Posttest } & $\begin{array}{l}\text { Experimental } \\
\text { Group } \\
\quad(\mathrm{N}=150)\end{array}$ & 80.15 & 3.15 & 0.03 \\
\hline & $\begin{array}{l}\text { Control Group } \\
(\mathrm{N}=150)\end{array}$ & 77.65 & & \\
\hline
\end{tabular}

Thorough analysis and comparison of pretest and posttest data and the analysis of SPSS17.0, following results are acquired. We draw conclusions: before the test, $\mathrm{t}$ and $\mathrm{p}$ are 0.17 and 0.74 
respectively, 0.74>0.05. After the test, the average score of experimental group exceeds that of pretest by more than 2 points and the average score of control group is 77.65, also higher than pretest score of 77.12 by 0.53 points. The average score of posttest experimental group is much higher than both pretest experimental and control groups. Meanwhile, after test $t=3.15, p=0.03<0.05$. Therefore, college English teaching based on SPOC flipped classroom outperforms traditional teaching mode in teaching effects.

\section{Conclusion}

College English teaching based on SPOC flipped classroom has not only transformed traditional teaching methods of spoon-feeding and one-size-fits-all, but also given new dimensions to translation classroom. It analyzes problems students encountered quantitatively and qualitatively in a small scale, solves them reasonably, displaying personalized and humane teaching tailored to different students. SPOC teaching mode has sparkled students' learning interest and boosted their confidence effectively. The integration of online and offline has prevented the disadvantages of MOOC substantially and injected new vitality into teaching by realizing the internalization and reinforcement of knowledge. From students' perspective, it stimulates their learning appetite and bolsters their confidence; from teachers' perspective, it brings out their creativity to help students use information resource to its greatest advantage and improve teaching effects.

\section{Acknowledgement}

This paper is supported by the fund from Planning Office of Philosophy and Social Science,Heilongjiang Province. Special Planning Projects. Project Number: 15EDD02

\section{References}

[1] Ministry of Education.10-Year Development Plan for Education Informationization (2011-2020) [Z].2011. (6) :5-6

[2] The Department of Higher Education. College English Curriculum Requirements [M].Shanghai: Shanghai Foreign Language Education Press.2007.6

[3] 马秀麟, 赵国庆, 鸟彤学. 大学信息技术公共课翻转课堂教学的实证研究[J].Journal of Distance Education, 2013,19 (1) 58-64

[4] 吕婷婷, 王娜. 基于 SPOC+数字化教学资源平台的翻转课堂教学模式研究[J].China Educational Technology, 2016.5: 85-90

[5] 康叶钦. 在线教育的“后 MOOC 时代”--- SPOC 解析[J].Research On Education Tsinghua University, 2014, (1): 86-93 